\title{
Freedom of Information Practices
}

\author{
Rick Snell
}

$\mathrm{T}$ The Australian High Court decision in McKinnon v Secretary, Department of Treasury [2006] HCA 45 has highlighted major differences in the handling of official access to government information in Australia and New Zealand. Despite commencing with similar legislative schemes and public policy objectives in 1983 the two countries have produced two very different national government information systems. New Zealand has a relatively open system in contrast to the relatively closed system in Australia. The more liberal disclosure approach in New Zealand has not generated the kinds of problems (less frank discussion in Cabinet, or disruptions to policy development) used by Australian officials as examples when they warn against more open disclosure practices.

While there are a number of critiques (for example, Price, 2005) of the New Zealand Official Information Act (OIA), they pale into insignificance compared to the nature and extent of the deficiencies identified with the Australian legislation and its administration (ALRC, 1995; Alhadeff, 2006; Fraser, 2003; Hubbard, 2005; Lamble, 2004; Lidberg, 2006; Commonwealth Ombudsman, 2006; Snell, 2000; Snell, 2002a; Snell, 2002b). The performance disparity between Australia and New Zealand noted in earlier research (Snell 2000) has widened significantly in the last six years.

In what follows we use the work of Stiglitz (2002), who analyses the role of information asymmetry in political and public policy. This provides a framework to further examine how this disparity in the performance of freedom of information legislation has occurred, and its implications for policy analysis and reform. In New Zealand the OIA has become a key reform which has allowed other public sector reforms to be implemented (Shroff, 2005:3). In Australia FOI has made a far more limited contribution to public sector reform. The aim of this paper is to identify some of the reasons for this difference and to add to the tools of analysis to assist future research and discussion.

\section{The International Backdrop}

When Australia, Canada and New Zealand adopted Freedom of Information legislation in 1983 a number of significant milestones were reached. First, the total number of countries with FOI laws had reached double figures 217 years after Sweden had enacted the first FOI laws. Second, it represented the first time that FOI had been adopted by countries with a Westminster system of government. Third, the push for further FOI uptake seemed to come to a standstill. It was not until the early 1990s that another country adopted national access legislation. Some authors have felt that big government and a liberal democratic heritage were

Rick Snell is a Senior Lecturer in law at the University of Tasmania. 
necessary conditions before issues like FOI could reach domestic agendas (Bennett, 1997:228). Others considered that the track record of FOI laws had been poor and uninspiring to potential reformers in other countries (Liddell, 2002).

The adoption of FOI legislation exploded between 1993 and 2006 when more than 70 countries adopted access legislation (Privacy International, 2006). This rapid uptake shows little sign of slowing as countries in the South Pacific (Fiji), Africa (Ghana), and the Caribbean (Bermuda) are in the process of passing legislation, and an estimated 50 more countries with efforts pending (Privacy International, 2006:16). The extent of this movement is further demonstrated by the rate of adoption of FOI in China. Since Shanghai (a special municipality) adopted FOI legislation in 2004 a further eight provinces and another special municipality (Chongqing) have adopted similar legislation (Qiao, 2006).

A number of factors have contributed to this unprecedented, in terms of rapidity and extent of uptake, global law reform movement including; globalisation requiring an increased access to information (Blanton, 2002:16-17), international human rights trends (Privacy International, 2006:9-16) anticorruption efforts (Transparency International, 2006) and efforts to improve governance and policy development (Stiglitz, 2002). Authors like Roberts (who provides a comprehensive coverage of these various trends) argue that there is now a global 'right to information' movement (Roberts, 2006:9).

Serious problems arise, or could develop, from this rapid law reform because of the limited number of models used to develop legislation - in particular the US model, and more recently the Article 19 Model Reforms (Article 19, 2001). These have tended to be the dominant design models considered by countries adopting FOI reforms. Lidberg would include the Swedish model but its influence has largely been restricted to a small group of Scandinavian countries (Lidberg, 2006:42). The dominance of the US model has been well demonstrated by Lamble (2003). Secondly,

The reforms are implemented with little consideration given to the way that state secrecy operates and the multi-dimensional impact of FOI which can provoke unexpected levels of non-compliance from those charged with administering the reform (Snell, 2004a:60).

Thirdly, serious problems arise if the initial flush of excitement promised by the reforms (significant and timely access to government information) is replaced by time consuming and frustrating failures to gain access. Rabin and Peled (2005) have outlined the frustrations and problems that have occurred in Israel where too little attention was paid to how best accommodate FOI legislation to existing political and bureaucratic culture.

Comparative law scholars have long debated whether law reform can be achieved by the simple measure of transplanting one legislative scheme to a new jurisdiction with little thought given to differences in culture, process and legal systems (Watson, 1974:10-15; de Cruz, 1999:213-224). Indeed Harlow argues that 'law is seen not merely as a toolkit of autonomous concepts readily 
transferable in time and space, but as a cultural artefact embedded in the society in which it functions' (Harlow 2000:3). Yet FOI law reform is dominated by the adoption of the US model or the use of 'model' laws proposed by NGOs or multilateral organizations (like Article 19, the Commonwealth Human Rights Imitative, or the Commonwealth Parliamentary Association).

\section{Access to government information in Australia and New Zealand}

A comparative analysis of two relatively long term schemes in Australia and New Zealand allows a better understanding of the design choices and approaches to public policy that have the potential to lead to the long term achievement of open government. Both countries started from similar positions as long term, stable liberal democracies with a strong Westminster system that heavily favoured official secrecy. Yet within 23 years the two countries, on any measurement of government openness, are operating very different government information regimes with the distance between the two systems continuing to widen.

Two examples, access to policy documents and to cabinet documents, allow the identification of important differences in the accessing of government information in Australia and New Zealand. An earlier study has explored why these two types of documents are both important and appropriate measures to use as comparisons (Snell, 2000:592-600).

In 2002 Michael McKinnon (National FOI Editor of The Australian, sought access, from the Australian Commonwealth Treasury, under the Freedom of Information Act (Cth) 1983 to policy documents relating to bracket creep and potential fraud of the First Homeowner's Scheme. The journalist was denied access to a range of documents including emails and briefing papers. On the eve of a hearing before the Administrative Appeals Tribunal (AAT) the government issued a series of conclusive certificates. These certificates precluded the availability of a merits review of the claimed exemptions (Paterson, 2005:230). The certificates are simply assertions that the information being sought are exempt and that it would not be in the public interest to release the requested material. In the McKinnon case the Secretary of the Treasury asserted that it would not be in the public interest to release the information because it was:

- $\quad$ likely to interfere with the capacity of public servants to give frank and direct advice;

- tentative advice;

- provisional advice;

- question time briefings;

- $\quad$ likely to lead to public officials not recording information;

- likely to have ongoing sensitivity; and

- likely to be taken out of context.

McKinnon was restricted to appealing the grounds for the issuing of the certificate, as opposed to the merits underpinning the claimed exemptions, a 
difficult task given the wording of the legislation and previous case law (Snell, 2004b). All the Government legal team had to show was that any one of the above seven claims could be demonstrated as being rational. The majority in both the Full Federal Court and the High Court decided that rationality only needed to be determined by looking at each claim in isolation and that there was no need to weigh those claims against other competing claims. Such competing claims included the benefits from allowing the information to inform discussion in the public arena, the extent to which the financial modelling could have assisted economic analysis or whether public servants would or ought to be timid and fearful when providing advice. All these claims can be considered central in any New Zealand decision about allowing access. In the subsequent AAT hearing, an appeal to the Full Federal Court and the final decision by the High Court, McKinnon and his legal team were unsuccessful in persuading the majority of judges to overturn the precedent and reasoning of previous decisions. Justices Heydon and Callinan did reject the last three of the points above as not being rational but determined that the other four grounds were reasonable grounds, when considered in isolation, for not releasing the requested information. Generally conclusive certificates will list several grounds in order to ensure that at least one survives scrutiny.

The majority judges, (Haynes, Heydon and Callinan) complained about the high level of abstraction associated with the case (the High Court did not look at any of the information at issue in the case) and were dismissive of McKinnon's witnesses because they had not seen the actual documents and therefore their evidence carried little probative value or relevance. The more liberal disclosure approach adopted by the Ombudsman and courts in New Zealand (see Commissioner of Police v Ombudsman [1988] 1 NZLR 385) would have ensured that the level of abstraction in such a case was kept to the minimum and that witnesses such as those used by McKinnon would have their views given due regard and attention.

The majority decision in McKinnon $v$ Secretary, Department of Treasury [2006] HCA 45 (Timmins, 2006) confirmed that the Australian Government was able, with little effort, to restrict access to policy documents that were in the lower end of the spectrum of sensitivity. The majority judges took little account of the wider policy objectives of the FOI Act - unlike their judicial counterparts in New Zealand and Canada - and restricted themselves to a very narrow interpretation of the legislation. The majority in McKinnon interpreted the case within a closed government framework. In contrast Justice Ruth McColl in General Manager, WorkCover Authority of NSW v Law Society of NSW [2006] NSWCA 84 at 154 stated:

freedom of information legislation, as the earlier discussion reveals, was intended to cast aside the era of closed government and principles developed in that era may, with the benefit of twenty or more years of experience, be seen as anachronisms. 
In a recent case study, involving nine separate FOI requests for access to documents in relation to kickbacks paid to the Hussein regime in Iraq by the Australian Wheat Board, Alhadeff was able to demonstrate the limited effectiveness of using FOI requests to access information (Alhadeff, 2006:19-23). Alhadeff concluded (p. 21):

Overall, the principal problem which Thomson's requests revealed is the government-fostered culture of frustrating contentious FOI requests. The responses received from DFAT suggests the decision-makers attempted to exempt as much information as possible, instead of reviewing requests with a view to releasing information unless there is 'good reason to withhold it'. It is this culture of resistance to access requests which represents the most significant challenge to FOI in Australia.

The McKinnon case required four years of persistence by the journalist and his organization and resulted in legal costs of over \$1 million (Timmins, 2006) for minimal information gain. Yet a request by the same media organization to the New Zealand Treasury for similar, but current, information was released within 24 hours (O'Sullivan, 2006). An extensive and detailed New Zealand research project reports a more mixed performance in relation to requests made under the OIA (Price, 2006). Price reported that the majority of requests were met in full, on time and that "many officials applied the OIA conscientiously and did not withhold information without careful and reasoned consideration of the grounds in the OIA' (Price, 2006:20). Yet Price raised a number of concerns including unnecessary delays; minimal justification for claims to exemptions; and that 'many agencies seemed to wrongly regard policy advice as constituting a class of documents that need not ever be released, and certainly not until the Minister has seen them'(Price, 2006:20).

The difference in allowing access to official information between Australian and New Zealand is at its starkest in relation to Cabinet documents. New Zealand allows access to cabinet documents if it can be demonstrated that the consequences of releasing the information does not outweigh the public interest in keeping the information confidential (Eagles, 1992; Buchanan, 1991:2). In contrast, once information in Australia meets the technical requirements of being classified as cabinet information it is automatically exempt (Paterson, 2005:8.348.64; Snell, 1993:42; ALRC, 1995:9.17-9.13). In Australia 'it is immaterial that it can be established that the requested information is outdated, of little consequence, or only incidental or not even relevant to the deliberations of Cabinet' (Snell, 2000:592).

The following list details successful requests for cabinet information under the OIA in New Zealand. Similar requests in Australia would have seen no information being released into the public domain via the FOI Act: 
- Cabinet papers for $\$ 14$ million funding for Maori development (The Dominion Post 17 Aug 2004).

- Cabinet papers for a $\$ 2.3$ million government programme for a cultural diplomacy international programme, launched by Prime Minister (The Dominion Post 3 May 2005).

- Cabinet papers revealing that the NZ government had ordered an urgent review of New Zealand's patchy tsunami-readiness systems because of concerns they were not adequate. (The Dominion Post 28 February 2005)

- Access given to Cabinet discussions about New Zealand's aid contribution. Bob Geldorf criticised New Zealand's aid efforts. An access request revealed that two years earlier two Labour cabinet ministers had raised similar arguments in Cabinet (Sunday Star Times 23 July 2006).

- The Sunday Star-Times was given the financial breakdown under the OIA of the cost of New Zealand's defence commitment to East Timor and also received cabinet papers showing April's violence left the UN undecided about its future in East Timor (Sunday Star Times 6 August 2006).

- Information released under the OIA revealed that high-risk paedophiles could be chemically castrated under a radical plan being considered by the government. The Cabinet papers revealed government departments here are divided over the proposal, amid fears it would breach the Bill of Rights and medical ethics (Sunday Star Times 11 January 2004).

- Cabinet papers reveal that due to manufacturing constraints and CSL's priorities, bird flu vaccine it would not be available in New Zealand for 15 to 27 weeks after the World Health Organisation declared a pandemic and New Zealand placed its order. New Zealand is third on CSL's list, after Australia and a small country in the region that neither CSL nor the ministry would name (7 February 2006).

- Cabinet papers, obtained by Radio New Zealand under the Official Information Act, show Treasury has deep concerns about the effectiveness of the public service's spending (20 April 2006).

The contrast with Australia extends even further than the potential to request cabinet documents to include their proactive release. In a 2005 speech Marie Shroff (2005:8), New Zealand's Privacy Commissioner and former Secretary of the New Zealand Cabinet, noted:

Look at any New Zealand government or state sector website and you will find the full text of Cabinet papers and Cabinet decisions and sometimes endless lists of discussion documents on highly sensitive matters of government policy, usually seeking public submissions. 


\section{Critical Choices in Design and Public Policy Objectives}

While the New Zealand OIA has a number of shortcomings and problems, in terms of compliance in certain areas of the bureaucracy (Price, 2006:20-21; Law Commission, 1997; Shroff, 2005:4-6), its performance in allowing access to policy documents and cabinet information is far superior to Australian legislation and practice. In part this differential performance can be attributed to several points of design difference between the two pieces of legislation (Snell, 2000) and to a clear policy choice (influencing design choices) between trying to achieve a more open information environment to improve public policy (New Zealand) and the Australian attempt to accommodate an FOI scheme into a traditional 'closed' Westminster system (Snell, 2002c:38-39). The taxonomy in Table 1 summarises some important design choices related to the two pieces of legislation. Shroff (2005:2) notes that the product of these choices

was a measure which turned the presumption on its head, decreed progressive availability of most official information; and was greeted with incredulity, and some alarm by a large number of public servants, I confess including myself.

Table 1: Design Differences between the FOI Act and OIA

\begin{tabular}{l|ll}
\hline \multicolumn{1}{c|}{ Key features } & \multicolumn{1}{c}{ Australia } & \multicolumn{1}{c}{ New Zealand } \\
\hline The target of access & Documents & Information \\
Interpretation & Narrow & Pro-disclosure \\
Withholding provisions & Categorical & Consequential \\
Public Interest & Specific & General \\
Internal Review & Yes & No \\
External Review & Legalistic & Informal \\
Administering the Act & Ad hoc and internal & Systematic and external \\
& & for 5 years \\
Designer Expectations & Hostile reception & Evolutionary \\
\hline
\end{tabular}

Source: Snell (2000:577)

Liddell argues that the key to the success of the OIA is that it states a guiding principle of availability, informed by the purpose of accountability and participation, as the foundation on which the Act is built' (Liddell, 2002). This guiding principle, reversing the 'old official secrets presumption' (Shroff, 2005:1), was used to design the legislation to operate within and to contribute to an open system of governance. The default settings in the New Zealand system were set towards facilitating openness unless there could be mounted good arguments to maintain secrecy. The Australian settings were designed, or allowed, to default 
towards secrecy (or to maintain a status quo of secrecy and confidentiality) unless there was a good reason to permit disclosure. This default approach is reflected in the majority decision in McKinnon but has been long acknowledged in the literature. Zifcak considered that the AAT had from its very first cases adopted a cautious approach that had 'increased rather than decreased over time' in interpreting the FOI Act (Zifcak, 1991:163). He argued that since 1983 considerations in favour of non-disclosure had been emphasized, rather than those supporting the release of information (Zifcak, 1991:163). In McKinnon, Justices Heydon and Callinan (at para131) were able to accept a line of argument whereby a 'practical consequence may be that one or more of the stated objects of the Act are thereby defeated.'

Jim Spigelman in 1972, now Chief Justice of NSW, recognised that

no statute or simple set of decisions will alter generations of received tradition. A new tradition of open government will emerge only through the practice of open government itself (Spigelman, 1972:175).

He argued that the cumulative experience of ministers, public servants, parliament, the judiciary and citizens would create a "new tradition of open government by the "cumulative impact of the release of information which has traditionally been withheld' (p. 176). The New Zealand experience demonstrates that it was possible to create this new tradition from a classical Westminster system yet the puzzle remains why the Australian experiment has been far less successful.

Compliance analysis was developed to try and explain the differential of FOI performance within jurisdictions. It argues that administrative compliance with FOI legislation is variable and that FOI performance is a complex interrelationship between design principles, type of administrative compliance and type of requesters as set out in Table 2. It was first developed by Roberts (1998) for Canada, and expanded and applied to Australia by Snell (2001). For instance heavy use by journalists seeking high level policy or sensitive documents is likely to shift the level of compliance from high administrative compliance to more negative types of administrative compliance such as adversarialism, noncompliance or malicious non-compliance. On the other hand, high-level use by individuals seeking access to information relating to their own personal affairs would be expected to generate behaviour in the higher compliance category such as proactive release or rapid processing. Zifcak argued that the administration of Australian FOI went smoothly as long as it occupied an institutional niche (processing personal affairs information by individuals) but soon became turbulent when more sensitive information to be used in public debate or the determination of public policy was the target of the access request for example increased usage by journalists, NGOs or opposition members of parliament (Zifcak, 1991:162). Other factors have been added to this complex interrelationship in recent years including the activities of spin doctors and contentious issues management (Roberts, 2005; Snell, 2002a), the roles and 
Table 2: Administrative compliance and Freedom of Information

\begin{tabular}{|c|c|c|c|c|c|}
\hline & $\begin{array}{c}\text { Malicious non } \\
\text { compliance }\end{array}$ & Adversarialism & $\begin{array}{l}\text { Administrative } \\
\text { non compliance }\end{array}$ & $\begin{array}{c}\text { Administrative } \\
\text { compliance }\end{array}$ & $\begin{array}{c}\text { Proactive } \\
\text { compliance }\end{array}$ \\
\hline & Shredding & $\begin{array}{l}\text { Automatic resort } \\
\text { to exemptions }\end{array}$ & $\begin{array}{l}\text { Inadequate } \\
\text { resourcing }\end{array}$ & $\begin{array}{l}\text { Requests handled } \\
\text { in a co-operative } \\
\text { fashion }\end{array}$ & $\begin{array}{l}\text { High priority to } \\
\text { processing } \\
\text { requests }\end{array}$ \\
\hline & $\begin{array}{l}\text { Deconstruction } \\
\text { of files }\end{array}$ & $\begin{array}{l}\text { Us versus them } \\
\text { mentality }\end{array}$ & $\begin{array}{l}\text { Deficient record } \\
\text { management }\end{array}$ & $\begin{array}{l}\text { Objective is } \\
\text { maximum release }\end{array}$ & $\begin{array}{l}\text { Objective is } \\
\text { maximum release } \\
\text { outside FOI }\end{array}$ \\
\hline & $\begin{array}{l}\text { Relabelling of } \\
\text { files }\end{array}$ & $\begin{array}{l}\text { Sitting on } \\
\text { requests }\end{array}$ & $\begin{array}{l}\text { Cost recovery or } \\
\text { minimisation } \\
\text { major factor }\end{array}$ & Timely decisions & $\begin{array}{l}\text { Information } \\
\text { identified and } \\
\text { available in public } \\
\text { interest - without } \\
\text { FOI requests }\end{array}$ \\
\hline & Sticky labels & $\begin{array}{l}\text { Significant } \\
\text { delays in } \\
\text { processing }\end{array}$ & $\begin{array}{l}\text { Low priority } \\
\text { attached to } \\
\text { processing of } \\
\text { requests }\end{array}$ & $\begin{array}{l}\text { FOI officers key } \\
\text { decision makers } \\
\text { about release }\end{array}$ & $\begin{array}{l}\text { FOI officers key } \\
\text { actors in agency } \\
\text { information } \\
\text { management }\end{array}$ \\
\hline & $\begin{array}{l}\text { Pre-emptive } \\
\text { exploitation of } \\
\text { exemptions }\end{array}$ & $\begin{array}{l}\text { Non-existent or } \\
\text { very poor } \\
\text { statement of } \\
\text { reasons even at } \\
\text { internal review } \\
\text { stage }\end{array}$ & $\begin{array}{l}\text { Adequate reason } \\
\text { statements but } \\
\text { often missing } \\
\text { aspects (No. of } \\
\text { documents being } \\
\text { withheld etc) }\end{array}$ & $\begin{array}{l}\text { Exemptions only } \\
\text { applied as a last } \\
\text { resort and to the } \\
\text { minimum extent } \\
\text { possible }\end{array}$ & $\begin{array}{l}\text { Exemptions } \\
\text { waived if no } \\
\text { substantial harm } \\
\text { in release. }\end{array}$ \\
\hline & $\begin{array}{l}\text { Fees used to } \\
\text { discourage } \\
\text { request }\end{array}$ & $\begin{array}{l}\text { Fee waivers } \\
\text { rejected }\end{array}$ & $\begin{array}{l}\text { FOI officers play } \\
\text { a processing role }\end{array}$ & & \\
\hline & $\begin{array}{l}\text { Internal reviews } \\
\text { uphold original } \\
\text { decision } 90 \%+ \\
\text { of times }\end{array}$ & $\begin{array}{l}\text { Internal reviews } \\
\text { uphold original } \\
\text { decision } 75 \%+ \\
\text { of times }\end{array}$ & $\begin{array}{l}\text { Internal review } \\
\text { seen as preparing } \\
\text { a better case for } \\
\text { external review }\end{array}$ & $\begin{array}{l}\text { Internal review } \\
\text { new decision }\end{array}$ & $\begin{array}{l}\text { Internal review an } \\
\text { opportunity to } \\
\text { refine information } \\
\text { handling }\end{array}$ \\
\hline & $\begin{array}{l}\text { External reviews } \\
\text { avoided }\end{array}$ & $\begin{array}{l}\text { External reviews } \\
\text { depicted as a } \\
\text { battle against } \\
\text { external } \\
\text { reviewer }\end{array}$ & $\begin{array}{l}\text { No feedback of } \\
\text { external review } \\
\text { findings into } \\
\text { decision-making } \\
\text { process }\end{array}$ & $\begin{array}{l}\text { External review } \\
\text { decisions used as } \\
\text { future guide }\end{array}$ & $\begin{array}{l}\text { Adverse external } \\
\text { review seen as a } \\
\text { quality control } \\
\text { check }\end{array}$ \\
\hline $\begin{array}{l}\text { Type of } \\
\text { information }\end{array}$ & & & & & \\
\hline Personal & & & & $\sqrt{ }$ & $\sqrt{ }$ \\
\hline Mid level policy & & & $\sqrt{ }$ & $\sqrt{ }$ & \\
\hline $\begin{array}{l}\text { High level } \\
\text { policy }\end{array}$ & $\sqrt{ }$ & $\sqrt{ }$ & $\sqrt{ }$ & & \\
\hline \multicolumn{6}{|l|}{$\begin{array}{l}\text { Type of } \\
\text { requester }\end{array}$} \\
\hline Individual & & & & $\sqrt{ }$ & $\sqrt{ }$ \\
\hline Active Group & & & $\sqrt{ }$ & $\sqrt{ }$ & \\
\hline Journalists & & & $\sqrt{ }$ & & \\
\hline Opposition MPs & & $\sqrt{ }$ & $\sqrt{ }$ & $\sqrt{ }$ & \\
\hline
\end{tabular}


approaches of FOI officials (Snell, 2002d), and the state of the record management and archives system in a particular jurisdiction or agency (Sebina and Snell, 2007).

While a valuable tool of analysis for comparing the FOI performance of government agencies in a particular jurisdiction (even comparing performance within and between agencies over time) compliance analysis is less effective in cross-jurisdictional comparisons. For instance Price's study indicates that noncompliance is a significant issue of concern for users within the New Zealand system (Price, 2006). Yet the impact, or negative influence, of non-compliant activities in an more open information system like New Zealand's might be expected to be of a different dimension and importance compared to such activity within a more closed system like Australia. Hence compliance analysis has not been able to develop a comparative tool to aid cross-jurisdictional analysis.

\section{An Information Economics Perspective}

Stiglitz's application of the concept of information asymmetry to the public sector seems to offer a model of analysis which can incorporate both the differences in FOI performance discussed earlier in terms of administrative compliance analysis, and can also be deployed as a comparative analysis (Stiglitz, 2002). In 2001 Akerlof, Spence and Stiglitz were awarded the Nobel Prize for their work exploring the economic implications of asymmetries of information in the private sector. Their work in the area of information economics concentrated on the dynamics of information imperfection. Stiglitz then extended information asymmetry analysis into the public sector and allocated a critical role to freedom of information legislation. Freedom of information for Stiglitz serves as both a mechanism to offset information asymmetry and performs an instrumental role in that it leads to improvements in policy and decision making (Stiglitz, 2002:33).

Stiglitz's information asymmetry analysis adds to, and improves, FOI analysis because it helps deepen the understanding of why secrecy or closed government attitudes often persist despite the clear intentions and language found in FOI legislation. The analysis has encouraged researchers to consider whether there may be important differences in the type, level and dynamics of information imperfection over time and between jurisdictions. This type of analysis has also encouraged a focus on the interrelation of FOI with other areas like records management, archives, communication policy, and the operation of parliament rather than a singular focus on FOI legislation itself. Nevertheless there has only been limited coverage or application of information asymmetry in the FOI literature (Alhadeff, 2006:17; Hubbard, 2004; Hubbard, 2005; Sebina, 2007).

Information asymmetries exist within both economic and political processes. These information asymmetries create a myriad of information problems faced by consumers and firms in the private sector and for citizens and governments in the public arena (Stiglitz, 2001:488). The public marketplace for good policy and ideas becomes distorted and inefficient the greater the information asymmetries 
between governments and citizens. Yet political processes inevitably entail asymmetries of information and often reward those who exploit those asymmetries (Stiglitz, 2001:522). Current management (the government or bureaucratic leadership) has an incentive (retaining of public office and power) to increase asymmetries of information to enhance their market power or to diminish the attractiveness of the alternative governmental team (Stiglitz, 2001:523). This potential decrease in the overall quality of governance is undesirable because it can affect political contestability.

Stiglitz argues that there are strong forces (as in the private sector) in the public market place that work to reduce transparency. Stronger transparency mechanisms (like a free press, FOI laws, campaign funding disclosure, and public interest disclosure laws) reduce the capacity and scope for action for Governments and their agents, expose mistakes and allow corruption to be discovered. Therefore these measures are often strongly resisted, under funded, neglected or poorly implemented. Furthermore secrecy, as an artificially created scarcity of information, allows governments and their agents to extract rents including corrupt payments or simply gift exchanges such as exclusive leaks to a journalist who assists the government's spin on an issue (Stiglitz, 2001:490).

Modern information theory perceives information and public management as public goods whose value is not solely determined by price but by its other values and that there are both costs and benefits with withholding or disclosing information (Stiglitz, 2002:28-29). Public accountability requires meaningful participation by citizens on an informed basis. Yet 'becoming informed implies a cost - the threshold in time, energy and interest that needs to be expended in order to obtain the information' (Stiglitz, 2002:33). In a closed or more secretive system the costs of becoming informed are far higher and the impact of secrecy far greater than in an open system.

Stiglitz limited his analysis to the role that FOI could play in providing incentives and a mechanism to acquire and transmit information. Yet information asymmetry can be applied to explaining the performance differential between FOI in Australia and New Zealand. The legislation for both countries was introduced in 1983 into environments with highly asymmetric information, and where government secrecy was considered a natural operating norm. In Australia the design choices accommodated and perpetuated the key features of this asymmetrical information regime by according a high level of blanket protection to cabinet and other information. This was extenuated by the adoption of conclusive certificates and a heavy reliance on the achievement of the policy objectives being left 'to the sum of atomised actions by unconnected individuals' (Terrill, 2000:31). Therefore, the incentives for secrecy remained relatively unchanged in Australia and the relatively random actions of individuals were confronted by Governments with 'institutional memory, specialized expertise and ... a longer term interest in influencing the evolution of case law' (p. 31).

In contrast, the design choices and mechanisms adopted for New Zealand's OIA were used to guide the government to 'increase progressively the availability of official information' (Section 4) to citizens both reactively to requests, and 
proactively to pre-empt requests. In New Zealand the public service and successive governments learnt to accept that official information was likely at some stage to enter the public domain. Therefore it was, and is, created and managed on that basis. Shroff (2005:9) reflected that:

If I, as a civil servant, write a Cabinet paper which I expect to be sought for public release I am going to be extraordinarily careful to get my facts right, to avoid trespassing into politics, to give comprehensive reasons for and against a proposal, and to think very carefully about my recommendations. My advice will therefore be balanced, accurate and comprehensive.

In the Stiglitz analysis this would be an expected outcome in an information environment that was moving towards a greater symmetry between citizens and governments. The focus of the system is at the front end of the process where key decisions about information and documents are made before any access requests. In contrast, the Australian expectation was that exemptions - especially Cabinet - would be used to protect the maximum information possible. Indeed the Cabinet information exemption has been amended (to include a wider source of documentation) in jurisdictions like Victoria and Queensland. In Australia the key decisions on access are reactive and are heavily coloured by the type of requester, type of information being requested and the political environment at the time of the request. All of these are key elements which compliance analysis would suggest could trigger various types of non-compliance activity (see Table 2).

The Australian approach has been to allow the Cabinet exemption to 'operate like an access buffer zone around the central core of government policy development and execution' (Snell, 2000:593; Sheridan, 1997). So in contrast to New Zealand position where policy advice is more carefully crafted because it may eventually enter the public domain, in Australia the FOI exemptions are seen as useful devices to hide information. Information that may not be well prepared has the capacity to embarrass or reveal shortcomings in policy or decision making. The Australian Treasurer Peter Costello in relation to the McKinnon case made the following observations (ABC, 2006):

This will become an obstacle to giving candid and fearless advice. Let me say to you, we do have candid and fearless moments in the Cabinet. This may surprise you. But it does happen. We would be far less fearless and candid in the Cabinet if we knew that the minutes were going to be released under FOI. That protection is very, very important to us.

Stiglitz's analysis of information asymmetry can also be used to improve and extend compliance analysis in the study of FOI. In particular, information asymmetry can be used to differentiate between the impacts of variable compliance within different information environments, allowing comparisons within jurisdictions and between jurisdictions including over time. Determination 
of the level of information asymmetry - high in New Zealand and Australia in 1983, medium-high in Australia 2006, and a low in New Zealand in 2006 allows better gauging of the impact of variable compliance within these different types of information environments. A series of requests by an opposition member of parliament (Alhadeff, 2006) for access to policy documents in relation to an organization involved in a high level inquiry (the Australian Wheat Board) in a medium-high level asymmetrical information environment is confronted with a high level of adversarial type of compliance (see Table 2). A request for details about a sensitive policy program in the middle of the 2005 New Zealand election campaign, in a low level asymmetrical information environment, produced a high level of proactive compliance when the Ombudsman fast tracked the request so that the electorate could be fully informed when they cast their votes.

Compliance analysis supplemented by information asymmetry allows us to differentiate between the impact of the non-compliance identified by Shroff (2005) and Price (2006) in New Zealand and the type, level and effect of the noncompliance identified in Australia by Alhadeff (2006), Snell (2001) and the Commonwealth Ombudsman (2006). Currently the asymmetry analysis being applied to FOI is very simplified but Stiglitz has argued that simplified models help to clarify thinking about complicated matters and are a necessary forerunner to more complicated and detailed models (Stiglitz, 2001:480). Future research and analysis will need to widen the scope of this analysis to take into account other developments beyond the focus on FOI in areas like records management, trends in e-government and e-democracy. Shroff (2005:3) argues:

So let's get freedom of information into proportion. It is part of a wider reform and development of democracy and society; it is a very important way for individual citizens to access information. But as I look back from 23 years into your future, FOI reform, although major, is one of a set of tools. Other increasingly powerful tools for open government include Parliamentary questions, select committees, commissions of inquiry, determined lobby groups, highly motivated individuals, independent agencies, the internet, the universities and academics, and of course the media.

\section{Concluding Remarks}

The plethora of countries that have recently introduced freedom of information laws, or have intentions to do so in the next decade, have much to learn from the comparative experiences of Australia and New Zealand. The Australian experience should warn against seeking an 'off the shelf' version of the legislation that is given a limited policy role; is viewed primarily as a means of allowing individual access; and where the key decisions under the legislation are reactive. The New Zealand OIA shows what can be achieved by starting from first principles, designing legislation suited to the local political and administrative 
culture, ensuring that the focus on the front end user and making the major objective the making, on progressive and proactive basis, more high quality policy information available on a timely basis to citizens.

Freedom of information analysis has, to date, been very limited. It has been orientated towards statute and case law, while its relationship to other areas such as policy analysis, records management, and privacy are relatively unexplored. Incorporating, however limited and simplistically, ideas like Stiglitz's information asymmetry is a useful step to understanding FOI.

Discussion about Australian FOI concentrates on the perceived threats to Cabinet practice and the disruption that would be caused to allow greater access to policy information. The focus has been on the supposed incapacity of the public to understand the nature of tentative or provisional advice, or to understand that a Minister's position before a Cabinet meeting might later change due to the requirements of Cabinet solidarity. It has also been supposed that public servants would hesitate to provide frank advice in the future. Yet the New Zealand experience demonstrates that while FOI has the capacity to cause embarrassment a more liberal disclosure approach has, as predicted by Stiglitz, produced a higher quality and more available public good namely considered and justified policy advice and information. The OIA has strengthened democracy in New Zealand, led to better informed decisions and a far higher quality of information for decision makers and citizens. Yet the Australian debate is still pre-occupied by the threats or damage that FOI can cause to a Westminster type system. The majority of the High Court in McKinnon's case accepted the idea that a highly asymmetrical information environment is the natural state in Australia and that FOI needs to be limited so as to minimise the dysfunction caused by the legislation.

\section{References}

Australian Broadcasting Commission (2006), 'High Court Decision to Impact on Future of FoI', 7.30 Report 29 August, http://www.abc.net.au/7.30/content/2006/s1727429.htm.

Article 19 (2001), 'Model Freedom of Information Laws, 10 August, http://www.article19.org/publications/law/standard-setting.html.

Australian Law Reform Commission and Administrative Review Council, (1995), Open Government: A review of the Federal Freedom of Information Act 1982 (ALRC 77/ARC 40).

Alhadeff, M. (2006), Denying the Public's Right to Know: A critique of the operation of the Freedom of Information Act 1982, Australian National Internships Program, October.

Bennett, C. (1997), 'Understanding Ripple Effects: The Cross-National Adoption of Policy Instruments for Bureaucratic Accountability', Governance 10(3), 213-233.

Blanton, T. (2002), 'The Openness Revolution: The Rise of a Global Movement for Freedom of Information' Development Dialogue 1:7-21. 
Buchanan,R. (1991), 'Cabinet, policy documents and freedom of information; The New Zealand experience', Freedom of Information Review 31:1-6.

Commonwealth Ombudsman. (2006), 'Scrutinising Government Administration of the Freedom of Information Act 1982 in Australian Government Agencies', Report by the Commonwealth Ombudsman, March.

De Cruz, P.(1999), Comparative Law in a Changing World, Cavendish Publishing, $2^{\text {nd }}$ ed.

Eagles, I., M.Taggert and G. Liddell (1992), Freedom of Information in New Zealand, Oxford University Press.

Fraser, R. (2003), 'The need for Freedom of Information — Digging In, Not Giving Up', Freedom of Information Review 103:2-8.

Harlow, C. (2000), 'Voices of Difference in a Plural Community', Harvard Jean Monnet Working Paper 03/00.

Hubbard, P. (2004), 'Accountability in the Grey Area: Employing Stiglitz to Tackle Compliance in a World of Structural Pluralism, a Comparative Study', Freedom of Information Review 111:26-32.

Hubbard, P. (2005), 'Freedom of Information and Security Intelligence: An economic analysis in an Australian context', Open Government: A Journal on Freedom of Information 1(3).

Lamble, S. (2003), Computer-Assisted Reporting and Freedom of Information, PhD Thesis, University of Queensland, November.

Lamble, S. (2004), 'Media Use of Freedom of Information Surveyed: New Zealand Puts Australia and Canada to Shame', Freedom of Information Review 109:5-8.

Law Commission (1997), Review of the Official Information Act, Report 40, Wellington.

Lidberg, J. (2006), 'Keeping the Bastards Honest: The Promise and Practice of Freedom of Information Legislation', PhD Thesis, Murdoch University.

Liddell, G. (1997), 'The Official Information Act 1982 and the Legislature: A Proposal' in The Official Information Act Seminar Papers: General Overview of Official Information and the Official Information Act, Legal Research Foundation, Wellington.

Liddell, G. (2002), 'Origins, Background and Scope of Freedom of Information, Personal Access and Data Protection Law: Convergence, Divergence or Parallel Tracks?' presented at International Symposium on Freedom of Information and Privacy, Auckland, 28 March.

O'Sullivan, F. (2006), 'NZ Says our Freedom of Information Laws Are Arcane', The Australian, 9 September.

Paterson, M. (2005), Freedom of Information and Privacy in Australia: Government and Information Access in the Modern State, LexisNexis, Butterworths.

Price, S. (2006), 'The Official Information Act: A Window on Government or Curtains Drawn?', Open Government: A Journal on Freedom of Information 2(1). 
Qiao, Z. (2006), 'Exploration and Practice in Promoting Shanghai Municipal Open Government Information', Government Information Quarterly 23:28-35.

Rabin, Y. and R. Peled (2005), 'Between FoI Law and Culture: The Israeli Experience', Open Government: A Journal on Freedom of Information 1(2).

Roberts, A. (1998), 'Limited Access: Assessing the Health of Canada's Freedom of Information Laws', Freedom of Information Research Project, School of Policy Studies, Queen's University, April.

Roberts, A. (2001), 'The Information Commons at Risk', pp. 175-201in Drache, D. (ed.), The Market or the Public Domain: Global Governance and the Asymmetry of Power, Routledge, London.

Roberts, A. (2005), 'Spin Control and Freedom of Information: Lessons for the United Kingdom from Canada', Public Administration 83:1-23.

Roberts, A. (2006), Blacked Out: Government Secrecy in the Information Age, Cambridge University Press.

Sebina, P. and R. Snell (2007), 'Information Flows - the Real Art of Information Management and Freedom of Information', forthcoming in Archives and Manuscripts 35.

Sheridan, H. and R. Snell (1997), 'Freedom of Information and the Tasmanian Ombudsman 1993-1996', University of Tasmania Law Review 16:107.

Shroff, M. (2005), 'The Official Information Act and Privacy: New Zealand's Story', Presented at 'FOI Live' 2005 Conference, London, 16 June.

Snell, R. and H. Townley (1993), 'The Cabinet Information Exemption: Theoretical Safeguards Exposed by a Tasmanian Case Study', Freedom of Information Review 46:4245 .

Snell, R. (2000), 'The Kiwi Paradox - A Comparison of Freedom of Information in Australia and New Zealand', Federal Law Review 575-616.

Snell, R. (2001), 'Administrative Compliance - Evaluating the Effectiveness of Freedom of Information', Freedom of Information Review 93:26-32.

Snell, R. (2002a), 'Freedom of Information and the Delivery of Diminishing Returns, or How Spin Doctors and Journalists Have Mistreated a Volatile Reform', The Drawing Board: An Australian Review of Public Affairs 2(3):187-207.

Snell, R. (2002b), 'Contentious Issues Management - the Dry Rot in FoI Practice?' Freedom of Information Review 102:62-64.

Snell, R. and J. Upcher (2002c), 'Freedom of Information and Parliament: A Limited Accountability Tool for a Key Constituency?', Freedom of Information Review 100:35-41.

Snell, R. (2002d), 'FoI Officers - a Constituency in Decline?' Freedom of Information Review 102:69-72.

Snell, R. (2004a), 'Is there a Role for Comparative Freedom of Information Analysis?: Part 1', Freedom of Information Review 113:57-60. 
Snell, R. (2004b), 'Conclusive or Ministerial Certificates — an Almost Invisible Blight in Freedom of Information Practice', Freedom of Information Review 113:9-12.

Spigelman, J. (1972), Secrecy: Political Censorship in Australia, Angus and Robertson.

Stiglitz, J. (2001), 'Information and the Change in the Paradigm in Economics', pp. 472540 in T. Frangsmryr (ed.), Les Prix Nobel, The Nobel Prizes 2001, The Nobel Foundation 2002.

Stiglitz, J. (2002), 'Transparency in Government', pp. 27-44 in World Bank, The Right To Tell: The Role of Mass Media in Economic Development, WBI Development Studies, Washington DC.

Terrill, G. (2000), 'Individualism and Freedom of Information', Freedom of Information Review 87:30-32.

Timmins, P. (2006), 'High Court Low Point for FoI', http://FoIprivacy.blogspot.com/2006_09_01_FoI-privacy_archive.html.

Transparency International (2006), 'Using the Right to Information as an Anti-corruption Tool', http://www.transparency.org/global_priorities/access_information.

Watson, A. (1974), Legal Transplants: An Approach to Comparative Law, Scottish Academic Press.

Zifcak, S. (1991), 'Freedom of Information: Torchlight but Not Searchlight', Canberra Bulletin of Public Administration 66:162-169.

I would like to extend my thanks to Graeme Wells for his very helpful editing of this article and his patience. I am also very grateful for the very valuable and extremely helpful comments provided by the referees. 